\title{
Inter-comparison of two land-surface models applied at different scales and their feedbacks while coupled with a regional climate model
}

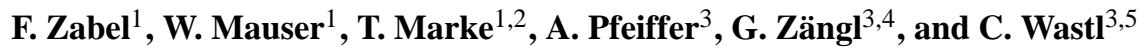 \\ ${ }^{1}$ Department of Geography, Ludwig-Maximilians-Universität (LMU), Munich, Germany \\ ${ }^{2}$ Institute of Geography and Regional Sciences, University of Graz, Austria \\ ${ }^{3}$ Institute of Meteorology, Ludwig-Maximilians-Universitt (LMU), Munich, Germany \\ ${ }^{4}$ Deutscher Wetterdienst (DWD), Offenbach, Germany \\ ${ }^{5}$ Department of Ecoclimatology, Technical University of Munich (TUM), Germany
}

Correspondence to: F. Zabel (f.zabel@iggf.geo.uni-muenchen.de)

Received: 12 July 2011 - Published in Hydrol. Earth Syst. Sci. Discuss.: 20 July 2011

Revised: 17 January 2012 - Accepted: 22 February 2012 - Published: 28 March 2012

\begin{abstract}
Downstream models are often used in order to study regional impacts of climate and climate change on the land surface. For this purpose, they are usually driven offline (i.e., 1-way) with results from regional climate models (RCMs). However, the offline approach does not allow for feedbacks between these models. Thereby, the land surface of the downstream model is usually completely different to the land surface which is used within the RCM. Thus, this study aims at investigating the inconsistencies that arise when driving a downstream model offline instead of interactively coupled with the RCM, due to different feedbacks from the use of different land surface models (LSM). Therefore, two physically based LSMs which developed from different disciplinary backgrounds are compared in our study: while the NOAH-LSM was developed for the use within RCMs, PROMET was originally developed to answer hydrological questions on the local to regional scale. Thereby, the models use different physical formulations on different spatial scales and different parameterizations of the same land surface processes that lead to inconsistencies when driving PROMET offline with RCM output. Processes that contribute to these inconsistencies are, as described in this study, net radiation due to land use related albedo and emissivity differences, the redistribution of this net radiation over sensible and latent heat, for example, due to different assumptions about land use impermeability or soil hydraulic reasons caused by different plant and soil parameterizations. As a result, simulated
\end{abstract}

evapotranspiration, e.g., shows considerable differences of max. $280 \mathrm{~mm} \mathrm{yr}^{-1}$. For a full interactive coupling (i.e., 2way) between PROMET and the atmospheric part of the RCM, PROMET returns the land surface energy fluxes to the RCM and, thus, provides the lower boundary conditions for the RCM subsequently. Accordingly, the RCM responses to the replacement of the LSM with overall increased annual mean near surface air temperature $(+1 \mathrm{~K})$ and less annual precipitation $(-56 \mathrm{~mm})$ with different spatial and temporal behaviour. Finally, feedbacks can set up positive and negative effects on simulated evapotranspiration, resulting in a decrease of evapotranspiration South of the Alps a moderate increase North of the Alps. The inconsistencies are quantified and account for up to $30 \%$ from July to Semptember when focused to an area around Milan, Italy.

\section{Introduction}

A multitude of studies deal with possible regional impacts of global climate change on a variety of land surface processes. These studies use the results of regional climate models (RCMs), which describe the processes in the atmosphere and at the land surface, thus, including atmosphere interactions both for oceans and land. Modelling climate, therefore, always requires an adequate representation of land surface processes within the climate model. The changing 
meteorological drivers are further used as input to downstream models which determine the impacts of the simulated climate change on the processes to be investigated. Downstream models are used to analyse the impacts of climate change on a broad palette of natural and/or societal developments and vulnerability including the land surface water cycle, land use and vegetation, agricultural yield and food security, human health, energy consumption, and many more (IPCC, 2007). Thereby, they usually focus on specific thematic questions that RCMs can not or only insufficiently address and on specific regions at high spatial resolution.

Nonetheless, the complexity and heterogeneity of land surface processes and the need for a more detailed view of the land surface is a long standing discussion in atmospheric sciences (Dickinson et al., 1991; Henderson-Sellers et al., 2008). There is evidence that more advanced and robust land surface models (LSMs), which increasingly consider the spatial heterogeneity (land-use, soil, elevation) and complexity of land surface biophysical and hydrological processes in the soil-plant-atmosphere continuum on an appropriate scale will reduce the uncertainties in the current modelling of landatmosphere processes (Essery et al., 2003; Hagemann et al., 2001; Molod and Salmun, 2002; Seth et al., 1994; Yu, 2000).

Meanwhile, hydrologists have developed empirical, conceptual and more and more physically-based land surface hydrological models (LSHMs) spanning a wide range of complexity. They include detailed descriptions of vertical and lateral soil water and energy flows, vegetation dynamics and related flow regulations, snow and ice dynamics as well as energy and mass exchange with the atmosphere and, thereby, cover the major land surface processes in the soil-plant-atmosphere continuum. However, in contrast to LSMs designed for atmosphere applications, the atmosphere is usually considered as an exogenous driver only.

At the same time as RCMs having become capable of physically downscaling the GCMs outputs to a resolution of $50-10 \mathrm{~km}$, LSHMs evolved from their original application in small watersheds to large basins. With the improving spatial resolution of the RCMs and the increasing areal coverage of the LSHMs, the scales covered by the two model families tend to converge (Chen et al., 1996; Henderson-Sellers et al., 1995; Yang et al., 1998). The RCMs' output at high spatial resolution now allows downstream impact models on the local to regional scale to use the results of RCM simulations offline as model input (Fig. 1a). By now, the hydrological community uses simulation results from RCMs as input for their LSHMs (Kotlarski et al., 2005). However, the LSHMs operating at the land surface usually represent land surface in a totally different manner than the LSMs used within the RCM.

Due to the different scales between impact models and RCMs and because of the huge numerical load the impacts are usually assessed with, downstream impact models are usually run offline. This means that they consider the meteorological outputs of the RCMs as exogenous input only and do not feed back to the atmosphere. However, land-

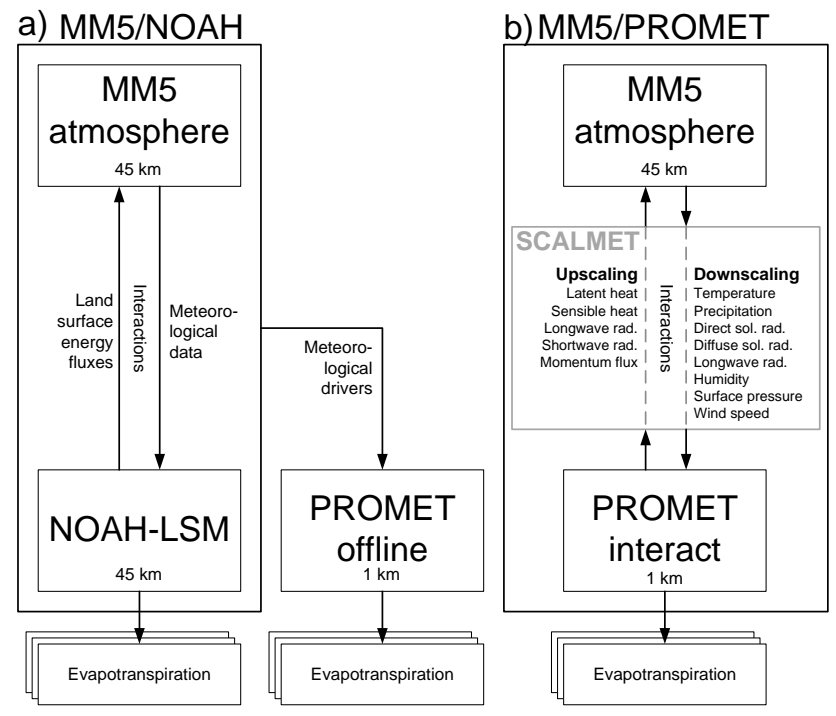

Fig. 1. (a) Principle of driving the hydrological model PROMET offline with data from the RCM MM5 within which the NOAHLSM provides the lower boundary conditions (left). (b) Interactive coupling of PROMET with the atmospheric part of MM5, thus, providing the lower boundary conditions via the scaling interface SCALMET (right).

atmosphere interactions are largely driven by soil moisture and soil temperature, vegetation dynamics and evapotranspiration as well as snow and ice dynamics (Fischer et al., 2007; Koster et al., 2004; Koster and Suarez, 1994; Martin, 1998; Orlowsky and Seneviratne, 2010; Pitman, 2003; Schär et al., 2004; Zeng et al., 2003). A consistent analysis of the regional impacts of climate change, therefore, would request to have the impact models directly coupled within the RCMs to be able to explicitly consider the feedbacks.

While coupling a RCM with a physically based hydrological downstream impact model offline, the model chain results in two LSMs - one within the regional climate and one within the impact model, both describing the same land surface processes (Fig. 1a). However, they are not identical which leads to inconsistencies within the offline model chain. They may have their causes in different scales between the LSMs, different coverage of land surface categories, different process descriptions and different parameterizations, etc. Although these inconsistencies are hardly ever quantified, they are only justified when land-atmosphere interactions are weak.

The following analysis uses a case study to compare two LSMs, one representing a LSM used within a RCM and a hydrological downstream climate impact model. It further aims at investigating the inconsistencies which arise due to different feedbacks from using the hydrological impact model offline and interactively integrated the impact model within the RCM (Fig. 1b). 


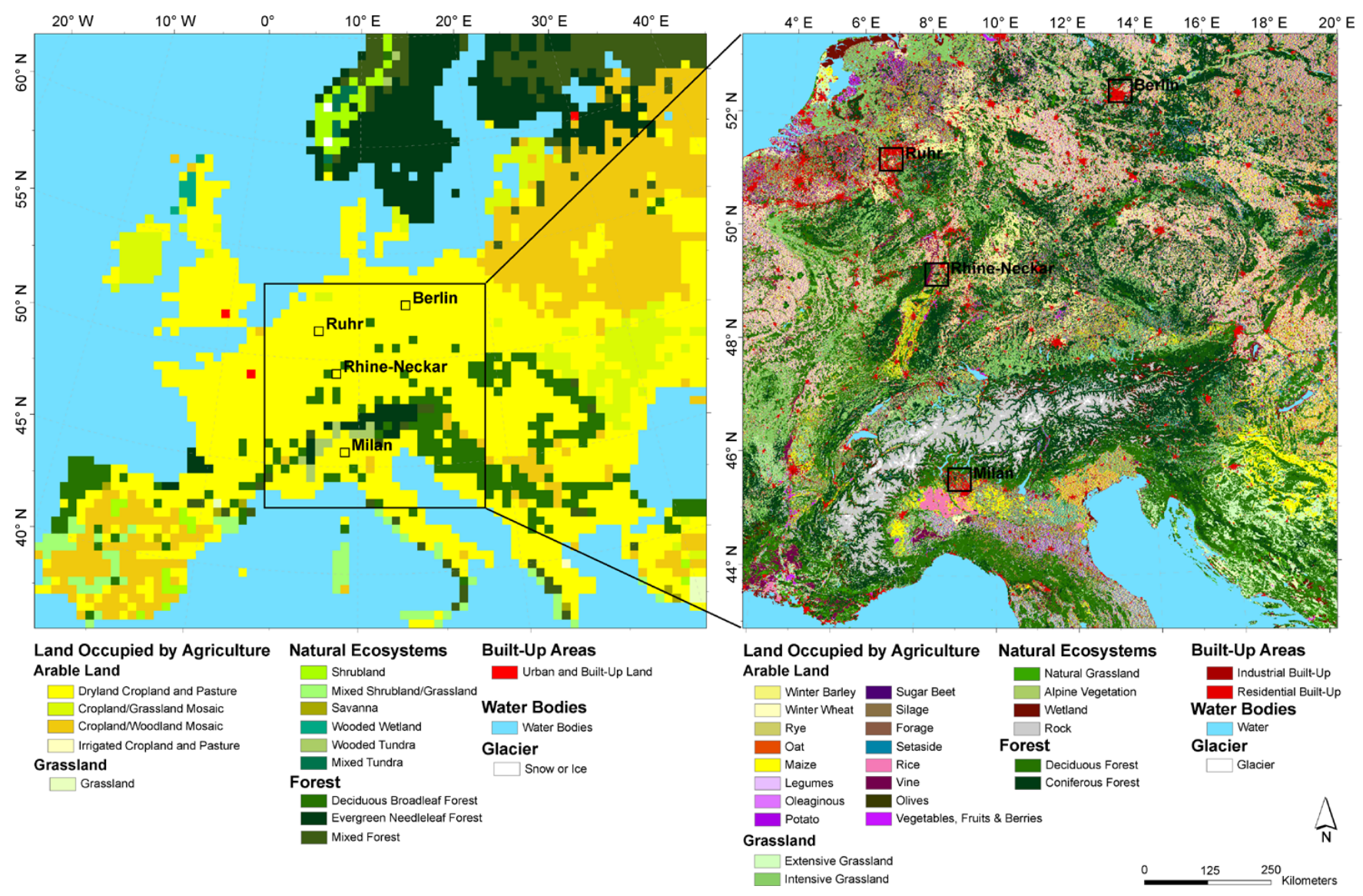

Fig. 2. Land use classification of the NOAH-LSM $(45 \times 45 \mathrm{~km})$ for the whole MM5 model domain and the inner coupling domain (left). PROMET land use classification $(1 \times 1 \mathrm{~km})$ for the coupling domain with MM5.

\section{Methods}

\subsection{Models and setup}

In order to describe the discrepancies and inconsistencies between a classical LSM used within a RCM and a LSHM, we applied the fifth-generation Mesoscale Model (MM5) (Grell et al., 1994) together with the NOAH-LSM (Chen and Dudhia, 2001a, b) at a spatial resolution of $45 \times 45 \mathrm{~km}$. Besides, from the hydrological model family, we applied the LSHM PROMET (Mauser and Bach, 2009) at a spatial resolution of $1 \times 1 \mathrm{~km}$. MM5 was modified and adapted to our specific simulation requirements and our model domain (Pfeiffer and Zängl, 2009; Zängl, 2002). The MM5 model domain covers most of the European continent and has a size of 79 gridboxes in West-East and 69 grid-boxes in South-North direction with the lower left corner at $\left(8.2^{\circ} \mathrm{W}, 35.6^{\circ} \mathrm{N}\right)$ and the upper right corner at $\left(43.2^{\circ} \mathrm{E}, 61.0^{\circ} \mathrm{N}\right)$ (Fig. 2) (Pfeiffer and Zängl, 2009). Lateral boundary conditions are provided 6hourly by ECMWF ERA-40 reanalysis-data (Uppala et al., 2005). The simulation was carried out from 1 July 1995 to 31 December 1999, using a spin-up time of 6 months for both models. The initial soil moisture conditions were set to field capacity $(\mathrm{pF}=2.3)$ in PROMET and are initialized using ERA-40 soil moisture data [Vol-\%] in NOAH.

While the NOAH-LSM was originally developed for the use in regional atmosphere applications, PROMET represents a LSHM, originally designed to study the impact of climate on hydrology on the local to regional scale. Due to the different demands on each of the models, they are supposed to differ in multiple aspects. Therefore, concerning this paper, we first conceptually compare both LSMs in terms of different scales, model physics and parameterizations. Further, evapotranspiration simulated both with the NOAH-LSM and coupled offline with PROMET (in the course of this paper named as PROMET-offline) are compared to each other (Fig. 1a). In this case, both models are using the same meteorological forcing. The model results of NOAH and PROMET-offline are compared to each other in order to quantify the differences when being forced with same meteorological data.

Interactions between the downstream model and the atmospheric part of the RCM are not possible within the offline coupled approach. Downstream models which are only weakly affected by feedbacks between the land surface and 
the atmosphere, e.g., those who study the effect of climate change on energy demand for heating buildings, may neglect that issue. However, the hydrosphere of the land surface strongly interacts with the atmosphere. Therefore, we further interactively (often also called 2-way, bidirectionally or bilaterally) couple PROMET with the atmospheric part of MM5, thereby replacing the NOAH-LSM in MM5 with PROMET. Thus, PROMET now provides the lower boundary conditions for the atmospheric part of MM5 (in the course of this paper named as PROMET-interact) (Fig. 1b). Another possible option by coupling the NOAH-LSM offline with meteorological data coming from the MM5/PROMET-interact simulation is not addressed in this study, since it is scientifically irrelevant regarding the downstream model approach.

Due to the substitution of the NOAH-LSM with PROMET, interactions between the RCM and the downstream hydrological impact model can now be taken into account. Consequently, the atmospheric part of MM5 responses to the replacement of the LSM. Therefore, we compare the temperature and precipitation output, simulated both with MM5/NOAH and with MM5/PROMET-interact, respectively. Finally, the impact of the feedbacks on simulated evapotranspiration is investigated by comparing the offline and the interactively coupled PROMET results.

A validation and comparison of the model results with measurements is beyond the scope of this paper, but will be dealt with in further studies.

\subsection{Coupling approach}

The interactions between the land surface and the atmosphere are based on the exchange of latent and sensible heat, short and longwave radiation as well as momentum (Campbell and Norman, 2000). Since the NOAH-LSM is an integral part of MM5, it is required within the RCM to model the land surface processes at the same temporal and spatial resolution as the atmospheric model components of MM5. PROMET differs from MM5 both in temporal and spatial resolution.

For the interactive coupling of PROMET with MM5, PROMET substitutes the NOAH-LSM within the coupling domain of MM5, extending $1170 \times 1170 \mathrm{~km}$ (Fig. 2). Consequently, the coarse meteorological data provided by MM5 $(45 \times 45 \mathrm{~km})$ has to be downscaled to the higher resolution of the land surface model $(1 \times 1 \mathrm{~km})$ for the coupling domain. Further, the surface fluxes simulated by PROMET at a resolution of $1 \mathrm{~km}$ have to be upscaled to the MM5 model resolution. This is done by applying the scaling tool SCALMET (Scaling Meteorological variables) (Marke, 2008; Marke et al., 2011). The statistical downscaling can either be used with regression based approaches (Daly et al., 2002) or empirical gradients (Liston and Elder, 2006), using elevationdependencies in order to scale the meteorological data to the fine resolution grid. The adjustable simulation time step within PROMET, which also constitutes the exchange time step between PROMET and MM5, is set to $9 \mathrm{~min}$ in the cur- rent study. This allows PROMET to run synchronously with MM5, which uses an internal time-step of $135 \mathrm{~s}$.

In addition to the offline downscaling approach, a 2-way (i.e., bidirectional) and, therefore, interactive coupling mode was implemented in SCALMET allowing for a linear upscaling of the scalar surface fluxes (see Fig. 2). In order to close the energy balance within the interactive coupled landatmosphere system, the downscaling as well as the upscaling approach strictly conserves mass and energy within the scaling processes in SCALMET for each variable. Hence, no bias correction is carried out in the framework of the model runs presented in this study. Therefore, any bias of the RCM is inevitably inherited by the LSM and vice versa.

\section{Study area}

The study area according to the coupling domain is situated in Central Europe and extends $1170 \mathrm{~km}$ North-South by $1170 \mathrm{~km}$ East-West including 18 European countries with the lower left corner at $3.9^{\circ} \mathrm{E}, 42.9^{\circ} \mathrm{N}$ and the upper right corner at $20.0^{\circ} \mathrm{E}, 53.3^{\circ} \mathrm{N}$. Plains like the Po and Upper Rhine Valley, uplands like in central Germany and mountainous regions in the Alps, which mark a climatic boundary between the temperate latitudes and the Mediterranean climate, compose a complex landscape. Altitudes are ranging from the Mont Blanc in the French Alps $(4810 \mathrm{~m})$ to the North Sea in the North-West and the Mediterranean Sea in the South. The area is characterised by intense agriculture especially within the fertile lowlands like the Upper Rhine or the Po Valley and densely populated areas such as the Ruhr region, Berlin, or Milan.

\section{Comparison of modelling approaches}

Since both applied models developed from different disciplinary background, the concepts behind the models vary in many aspects. While the goal of the development of the LSM was to implement an appropriate LSM for weather prediction and climate simulations, PROMET was developed for hydrological river catchment studies on the local and regional scale. A complete description of the NOAH-LSM is given by Chen and Dudhia (2001a, b) and Mitchell (2005). A comprehensive model description of PROMET can be found in Mauser and Bach (2009).

Nevertheless, both models describe the pathways of water and energy at the land surface in a physically based manner, thus, conserving mass and energy and closing the energy balance at the land surface without a calibration. They are describing the same land surface processes on different scales, thereby using different formulations and parameterizations. Thus, the model results basically must be comparable and the differences between the model results must be traceable to the conceptual differences. 

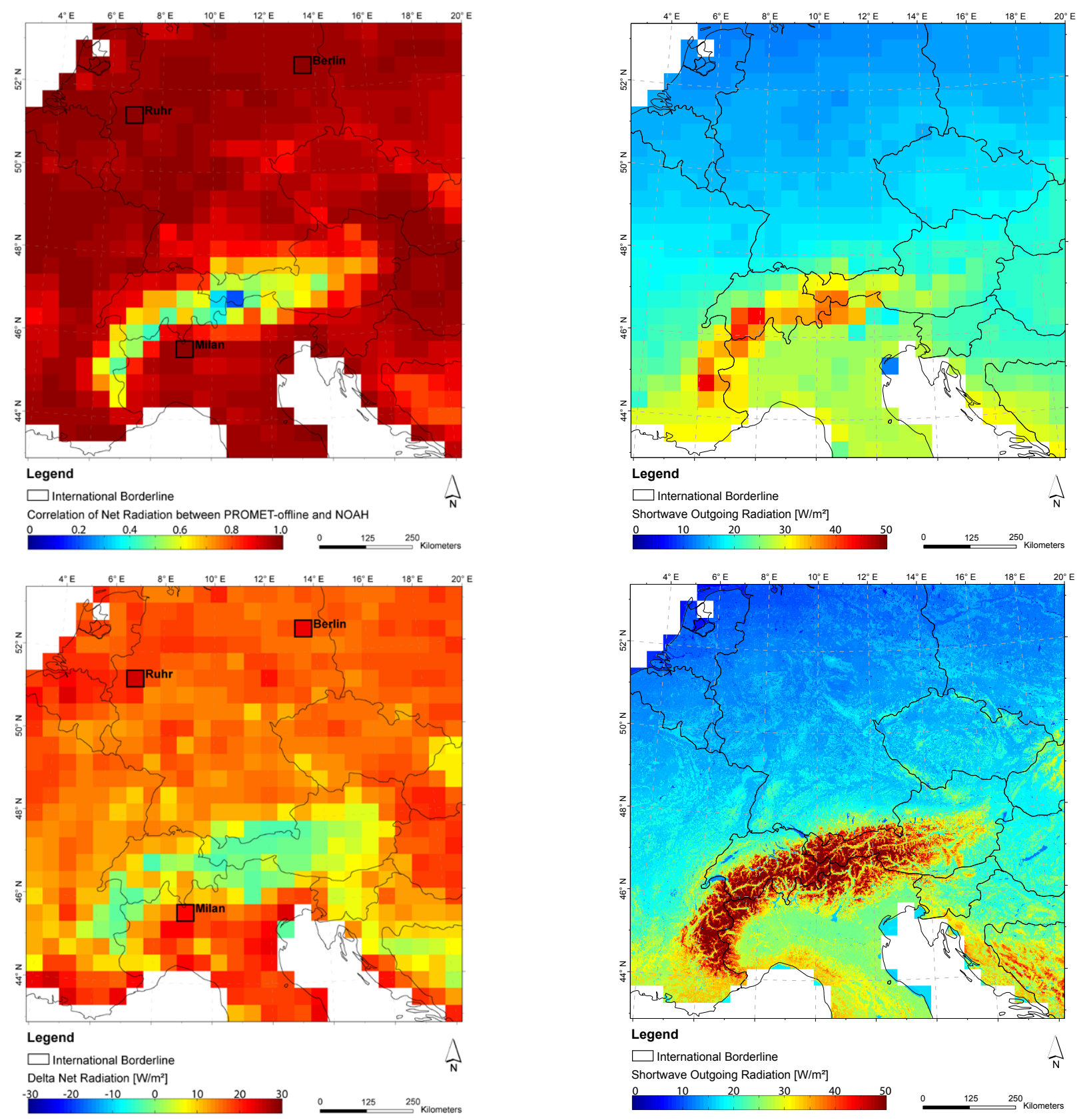

Fig. 3. Correlation $(r)$ of net radiation between PROMET-offline and NOAH for daily mean values (upper left) and difference plot of annual mean net radiation between PROMET-offline and the NOAH-LSM, scaled to the MM5 spatial resolution (lower left).

\subsection{Scales}

One major difference is the differently applied spatial resolution. Within the GLOWA-Danube project, in which this study took place, MM5 and, thus, the NOAH-LSM was applied in climate mode with a single domain having a horizontal spatial resolution of $45 \mathrm{~km}$ and an integration internal time step of $135 \mathrm{~s}$. The coarse spatial resolution was set

Fig. 4. Annual mean shortwave reflection $\left[\mathrm{W} \mathrm{m}^{-2}\right]$ (1 January 1996-31 December 1999) of the NOAH-LSM (upper right) and PROMET-offline (lower right).

in order to be able to simulate long time series for regional climate scenarios until the year 2100 with the available computational resources.

PROMET was applied at $1 \mathrm{~km}$ spatial resolution since it has been extensively validated in different regions in the world at $1 \mathrm{~km}$ spatial resolution (Mauser and Bach, 2009).

Due to the different spatial resolution, the models' underlying land-use (Fig. 2), the digital elevation model (DEM) as well as the soil textures vary in spatial heterogeneity. 

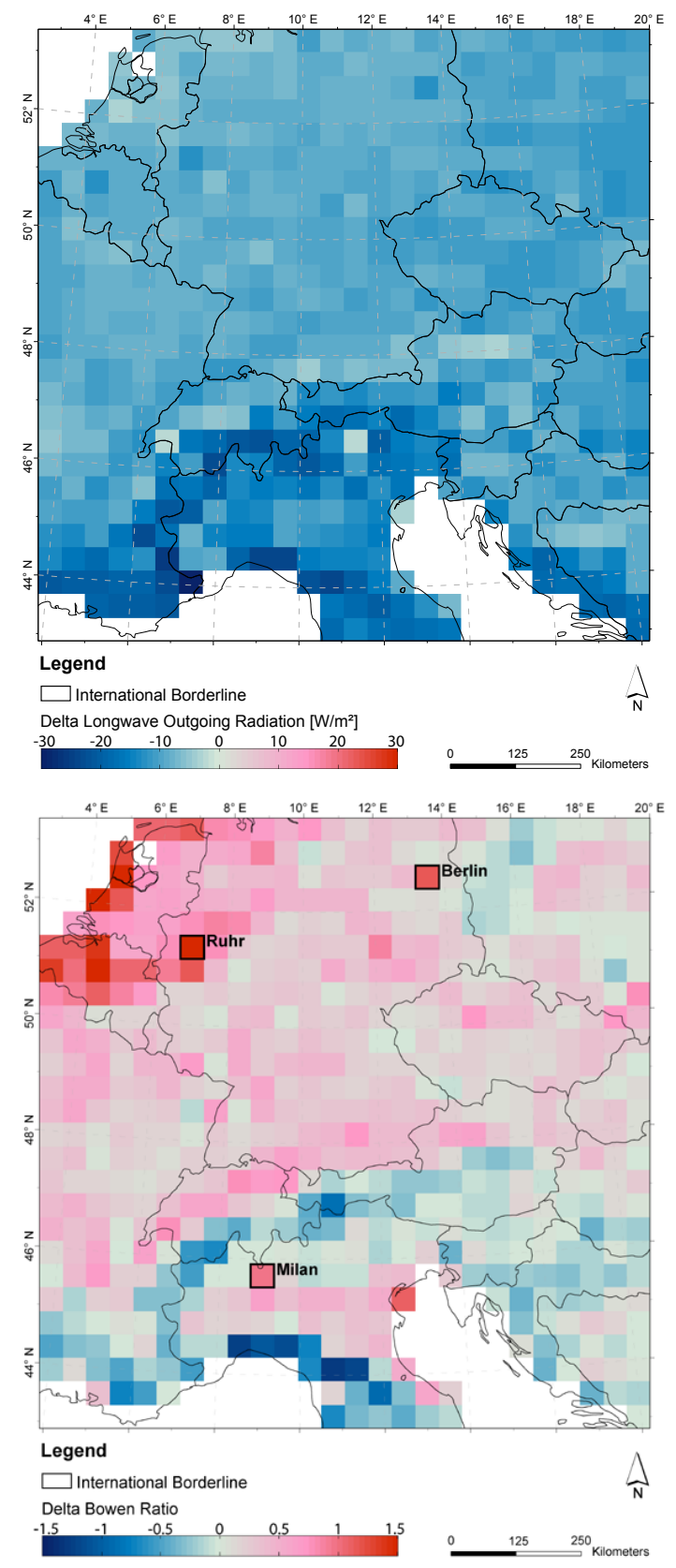

Fig. 5. Difference plot of annual mean longwave outgoing radiation between PROMET-offline and the NOAH-LSM (upper) and difference plot of annual mean Bowen ratio between PROMET-offline and the NOAH-LSM (lower), each scaled to the MM5 spatial resolution.

\subsection{Land use}

The land cover information has a strong effect on albedo, emissivity and partitioning of energy and matter fluxes from the surface to the atmosphere (Ge et al., 2007). Land cover determines the type of vegetation and, thereby the seasonal development of plant phenology, canopy structure and leaf area, which in turn, through vegetation height and leaf area index, determines the aerodynamic and evapotranspirative properties of the land surface. The combined vegetation and soil properties determine soil moisture development and the reaction of the land surface to changing fractions of latent and sensible heat fluxes influenced by vegetation water stress. Figure 2 shows the land use classifications used by NOAH and by PROMET, respectively.

Impervious surfaces such as scattered urban areas are not classified in the NOAH classification, since they are small scaled and, thus, not mapped at the coarse resolution in NOAH. While most of the land is homogeneously treated as one class of mixed arable land in NOAH, PROMET separates arable land into 17 individual crop types using different crop specific parameterizations. A detailed description of the land use/cover map used in PROMET is given in Zabel et al. (2010).

For example, while for Berlin, the Ruhr Region or Milan, NOAH classifies one class representing a mixture of dryland, cropland and pasture, the $45 \times 45$ respective upscaled PROMET pixels for each of the same area show a high share of urbanization - e.g., Berlin: $43 \%$, Ruhr region: $55 \%$, Milan: $37 \%$ (Fig. 2).

\subsection{Plant parameterization}

The parameterization for each of the vegetation types in PROMET is taken from literature and remote-sensing data (Bach, 1995; Mauser and Bach, 2009). Typical daily change of the dynamic plant parameters (LAI, albedo, root depth and plant height) were taken from the analysis of time series of LANDSAT images in Southern Germany in combination with extensive field measurements on typical plant stands (Mauser and Bach, 2009), thereby taking into account phenological behaviour of different stands and spatial heterogeneity (Zabel et al., 2010).

On the other hand, MM5 uses monthly values of green vegetation fraction (also known as $F_{\text {cover }}$ ) for each grid cell at the model's spatial resolution in order to allow for seasonal phenological behaviour of vegetation. The green vegetation fraction is derived from remote-sensing NDVI data and accordingly is also used within the NOAH-LSM to control the degree of urbanization and impervious surfaces for each grid cell. Due to known problems in NDVI scaling (Bach and Verhoef, 2003; Gutman and Ignatov, 1997; Richter and Timmermans, 2009), vegetation fraction was generally decreased by 30 percent which helped to improve the simulation of summertime near surface temperature substantially (Pfeiffer and Zängl, 2009).

\subsection{Soil water hydraulic and plant physiology}

Besides different underlying soil textures, the models use different physical approaches to describe the pathway of water through the soil and the plant into the atmosphere. Here, 

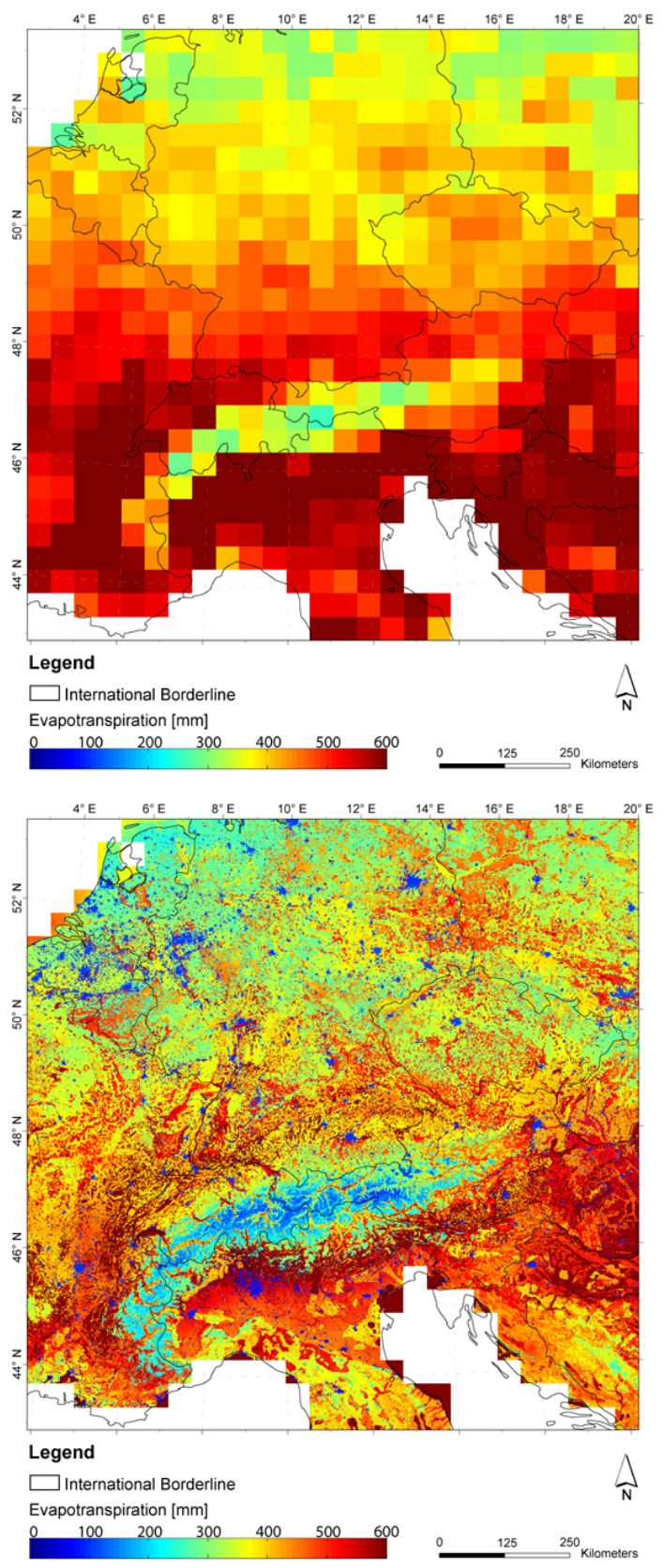

Fig. 6. Annual mean evapotranspiration of NOAH-LSM (upper) and PROMET-offline (lower).

PROMET uses a more comprehensive approach, following Baldocchi et al. (1987) and Jarvis (1976), taking more soil and plant specific parameters into account. NOAH uses soil specific water contents [Vol-\%] to parameterize wilting point, saturation and field capacity for calculating plant transpiration, while PROMET calculates soil water content from soil water potential and takes plant specific functions of leaf water potential into account, including a functional dependence between stomatal conductance and plant suction when calculating plant transpiration.

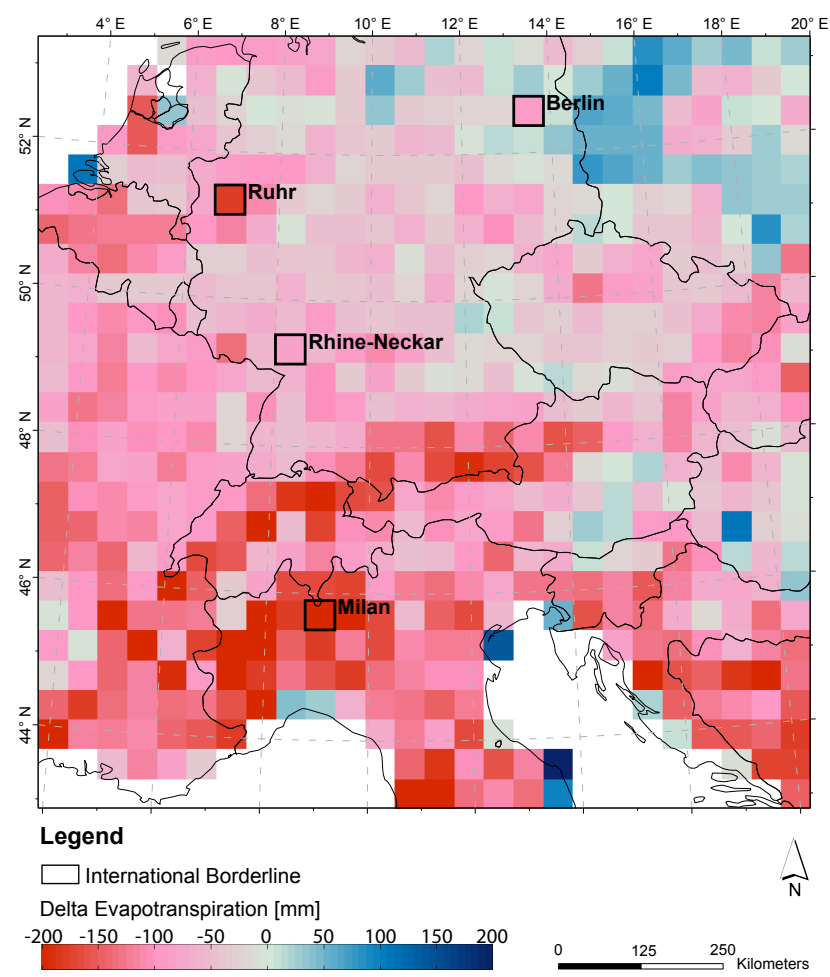

Fig. 7. Difference plot between PROMET-offline and NOAH-LSM showing the annual mean evapotranspiration.

\section{Results and discussion}

\subsection{Comparing NOAH and PROMET-offline}

The offline coupled model approach results in two LSMs, namely the NOAH-LSM and PROMET. The differences between the two models described in Sect. 4, result in different portioning of latent and sensible heat, while incoming solar radiation, temperature and precipitation are the same for both models in offline configuration (see Fig. 1a). As a result, net radiation shows a high temporal correlation between PROMET and NOAH, except for Alpine areas (Fig. 3). Here, large differences in snow cover affect shortwave reflection and, thus, net radiation. Nevertheless, the PROMET net radiation in the remaining domain is higher than the NOAH net radiation (Fig. 3), due to different land surface properties in terms of emissivity and albedo. Overall, more energy is available at the PROMET land surface (Fig. 3).

While albedo is handled as a prognostic variable in both LSMs, snow cover is less dominant in the Alpine regions in the NOAH simulation due to the use of different snow modules and lower altitudes in mountainous regions caused by scale issues. Due to the higher spatial resolution in PROMET, spatial heterogeneity - especially in mountainous regions can be captured more realistically. Thus, not only snow processes, but also radiation processes can be 


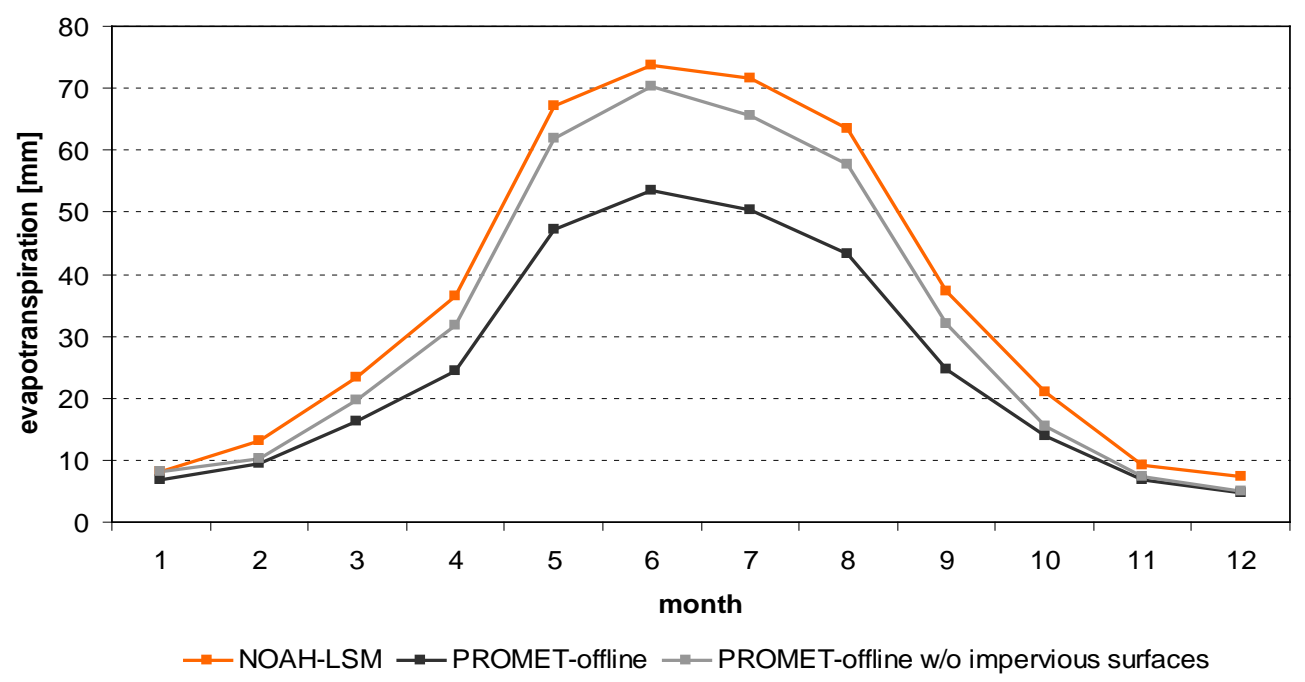

Fig. 8. Monthly mean evapotranspiration from 1996-1999 simulated by the NOAH-LSM and PROMET-offline for pixels, dominated by impermeable area (share $>20 \%$ ) in the upscaled PROMET land use. The PROMET-offline results are shown for all corresponding PROMEToffline pixels as well as for vegetated pixels only, neglecting impervious surfaces.

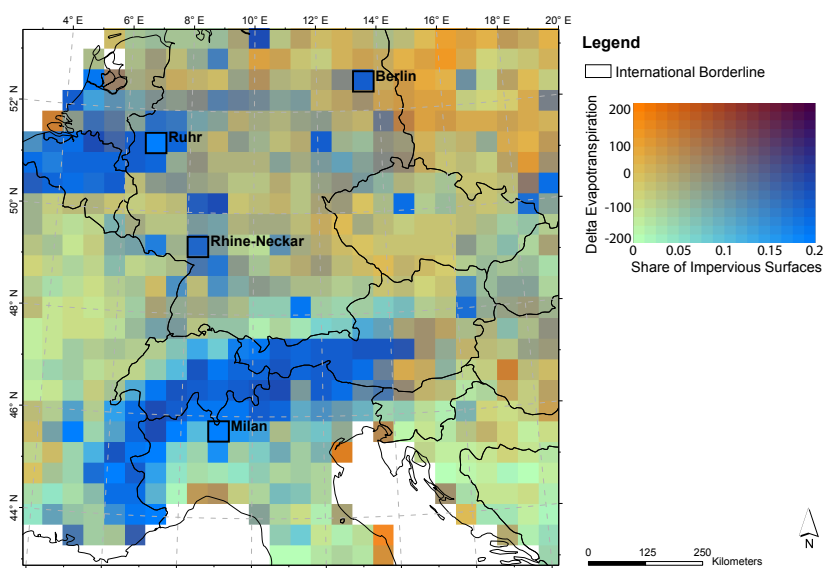

Fig. 9. Upscaled share of impervious area of the PROMET land use versus the difference of evapotranspiration between PROMEToffline and NOAH, illustrated with a bivariante colour map (Teuling et al., 2011).

calculated with higher spatial and process detail considering, e.g., aspect, slope and altitude more accurately.

Consequently, shortwave reflection increased mainly in the Alpine part of the model domain (Fig. 4), reducing net radiation in winter and spring in the PROMET simulation, while net radiation is increased in the summer months, when the snowpack has melted in mountainous regions.

The higher net radiation in the PROMET simulation in the non-alpine areas mainly is due to differently assumed emissivities of the land surfaces, resulting in overall lower emissivity and, therefore, lower longwave outgoing radiation in the PROMET simulation (Fig. 5, upper).
Further, the different portioning of the available energy at the land surface into latent and sensible heat is shown in Fig. 5 (lower) by subtracting the annual mean Bowen ratio. Finally, more available energy at the land surface is proportionally given more into sensible than into latent heat in the PROMET simulation, where finally the Bowen ratio remarkably increased in areas with high share of urbanization (Fig. 5). The degree of urbanization shows a correlation of 0.71 with the difference plot of the Bowen ratio.

Figure 6 compares the annual mean evapotranspiration from 1996-1999 simulated by the NOAH-LSM (upper) and by the offline PROMET approach (lower). Regarding the hydrological context of this paper, latent heat is shown as evapotranspiration in [mm]. Overall, the NOAH-LSM simulation shows an annual mean evapotranspiration of $469 \mathrm{~mm}$ and PROMET-offline $397 \mathrm{~mm}$ respectively. The remarkable mean difference of more than $70 \mathrm{~mm}$ for the area average is diversely spatially distributed and has several reasons that we further aim to investigate.

Basically, both models show a north-to-south gradient of evapotranspiration and lower values in the Alpine region, which corresponds to the prevailing climate conditions. Daily mean values of the model domain are highly correlated between the models $\left(R^{2}=0.94\right)$. The most obvious difference is the spatial heterogeneity related to the spatial resolution applied to each model. The PROMET-offline evapotranspiration allows for recognising small-scale spatial patterns such as Alpine valleys with high contrasts to its surroundings and forested areas with high evapotranspiration as can be found e.g., in the Black Forest (approx. $48.5^{\circ} \mathrm{N}, 8.3^{\circ} \mathrm{E}$ ). While the PROMET land-use data set includes a number of impervious surfaces (residential or industrial areas and rocks) that do not contribute to transpiration and, therefore, 

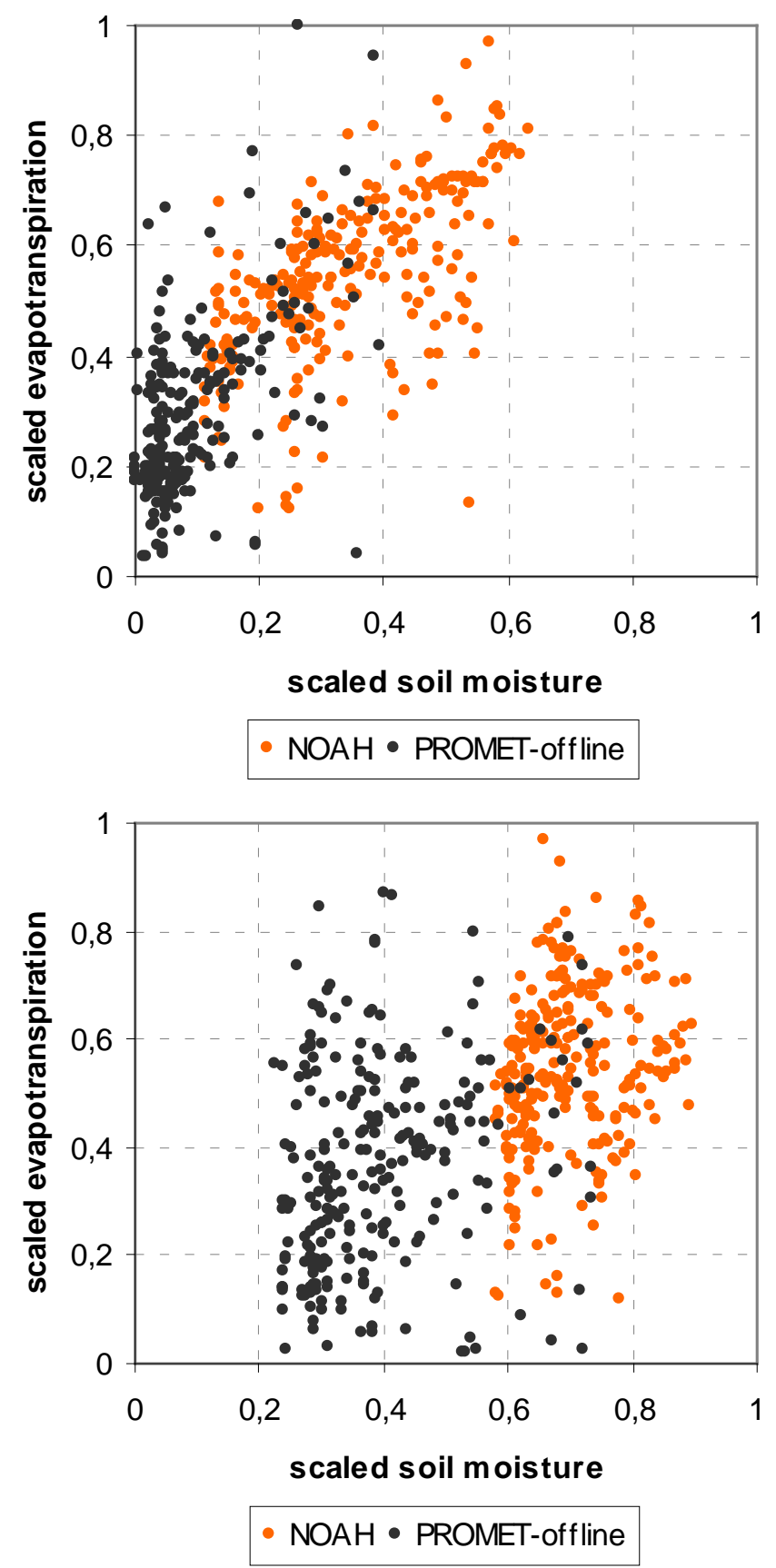

Fig. 10. Daily mean evapotranspiration (normalised by maximum) plotted against soil moisture of the third soil layer (scaled between wilting point and saturation) for the NOAH-LSM and PROMEToffline, showing the vegetated pixels of the Milan area (upper) and the Rhine-Neckar area (lower) for July and August (1996-1999).

reduce annual mean evapotranspiration, the NOAH underlying land-use dataset accounts only for a small number of land-use classes and mainly implements cropland in the model domain (Fig. 2). The effect of different land-uses and impervious surfaces in PROMET becomes especially apparent in large urban areas such as Berlin or the extended Ruhr

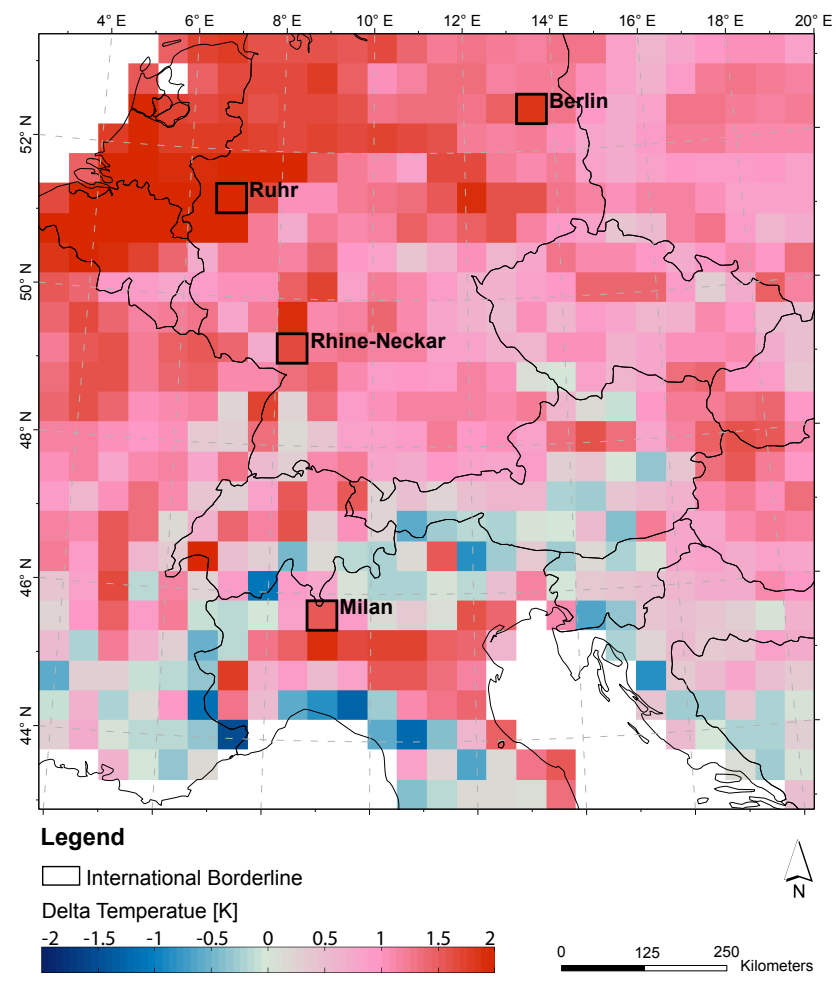

Fig. 11. Subtraction image (MM5/PROMET-interact MM5/NOAH) of the annual mean near surface air temperature [K] (01 January 1996-31 December 1999).

region as well as in rocky Alpine areas (Fig. 6). In order to compare the model results on the same spatial scale, we aggregated the PROMET-offline result to the spatial resolution of $45 \times 45 \mathrm{~km}$ and finally subtracted it from the NOAH evapotranspiration (Fig. 7).

The highest difference of evapotranspiration can be found at the Milan pixel. Here, evapotranspiration is reduced by $283 \mathrm{~mm}$ from $707 \mathrm{~mm}$ (NOAH) to $424 \mathrm{~mm}$ (PROMET-offline).

Further, Fig. 8 compares the models' evapotranspiration by assuming a similar land use in both models. For this purpose, impermeable areas are ignored when upscaling the $1 \times 1 \mathrm{~km}$ PROMET evapotranspiration to the MM5 spatial resolution. Figure 8 shows the monthly mean values only for pixels with a share of impermeable area of at least $20 \%$ in the upscaled PROMET land use classification. Thereby, different assumptions in the LSMs' underlying land use classification in terms of impervious surfaces result in great differences in summer (up to $21 \mathrm{~mm} \mathrm{month}^{-1}$ in July) and small differences in winter $\left(1 \mathrm{~mm} \mathrm{month}^{-1}\right.$ in January). By neglecting impervious surfaces, the prominent annual gap of $130 \mathrm{~mm} \mathrm{yr}^{-1}$ is reduced to $46 \mathrm{~mm} \mathrm{yr}^{-1}$ and the difference in July is reduced to $6 \mathrm{~mm} \mathrm{month}^{-1}$ (Fig. 8).

For a spatially differentiated consideration of the impact of impermeable areas for the coupling domain, Fig. 9 


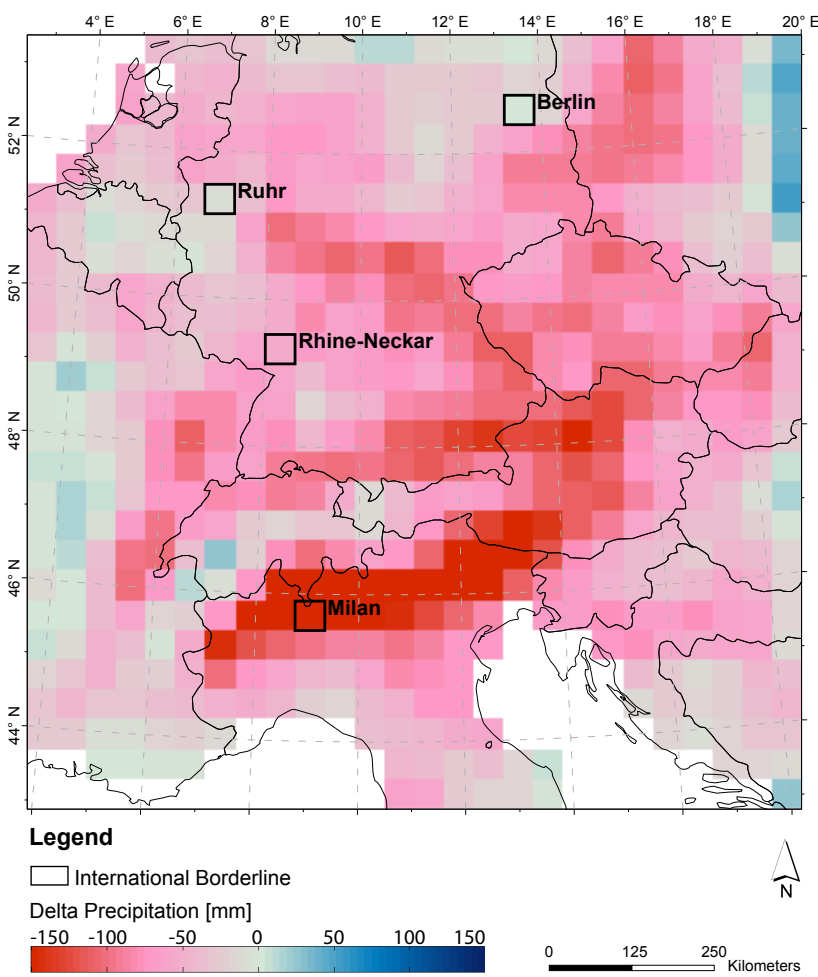

Fig. 12. Subtraction image (MM5/PROMET-interact MM5/NOAH) of the annual precipitation [mm] (1 January 199631 December 1999).

shows the difference of simulated evapotranspiration between PROMET-offline and NOAH versus the upscaled share of impermeable land in the PROMET land use classification, illustrated with a bivariante colour map (Teuling et al., 2011).

Another important aspect contributing to inconsistencies are due to different soil hydraulics, affecting soil moisture and, therefore, soil evaporation and plants transpiration. The functional dependence between soil moisture of the third soil layer and evapotranspiration for the Milan and RhineNeckar vegetated pixels for daily values in July and August is shown in Fig. 10 for each model. Scaled between saturation and wilting point, PROMET operates in a drier part of the sensitivity curve, thereby more restricting evapotranspiration than the NOAH-LSM (Fig. 10). PROMET reacts more sensitive to increasing soil suction and decreasing soil moisture, respectively. While the wilting point is never reached in the Rhine-Neckar area, it is already reached on several days in the PROMET-offline simulation from July to August in the Milan area (Fig. 10). The soil layer thickness of the third soil layer is $1 \mathrm{~m}$ in both models, reaching from 1 to $2 \mathrm{~m}$ in the NOAH-LSM and from 0.5 to $1.5 \mathrm{~m}$ in PROMET, respectively.

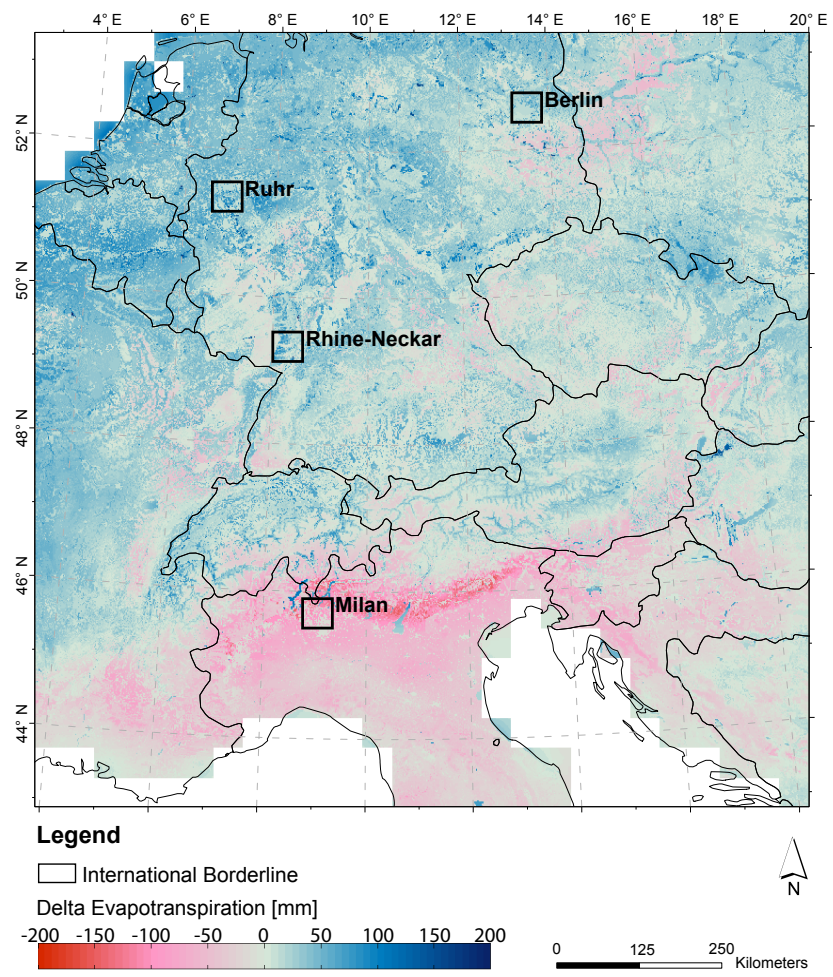

Fig. 13. Subtraction image of PROMET-interact and PROMEToffline simulation for annual mean evapotranspiration $(1 \times 1 \mathrm{~km})$.

\subsection{Quantification of feedbacks using PROMET-interact}

The simulated latent and sensible heat between the NOAHLSM and PROMET-offline, as showed differ both in spatial and temporal manner. When using PROMET instead of NOAH within MM5, the response of the atmosphere to the changed land surface fluxes now result in feedbacks that in turn affect the land surface energy fluxes. Thus, the inconsistencies within the offline coupling approach due to neglecting those feedbacks are quantified. Therefore, PROMET is now interactively coupled with MM5, thereby substituting the NOAH-LSM and finally providing the lower boundary conditions for the MM5 atmosphere (Fig. 1b). Energy conservation is guaranteed within the interactively coupled system. The feedbacks can amplify or dump an initial perturbation to the system. As a result, a new equilibrium between the land surface and the atmosphere establishes and, therefore, changes the energy fluxes in both directions. This chapter first describes the responses of the MM5 atmosphere triggered by the replacement of the LSM. Finally, the impact of feedbacks on the interactively coupled PROMET (PROMET-interact) evapotranspiration is investigated and compared against the PROMET-offline simulation. 


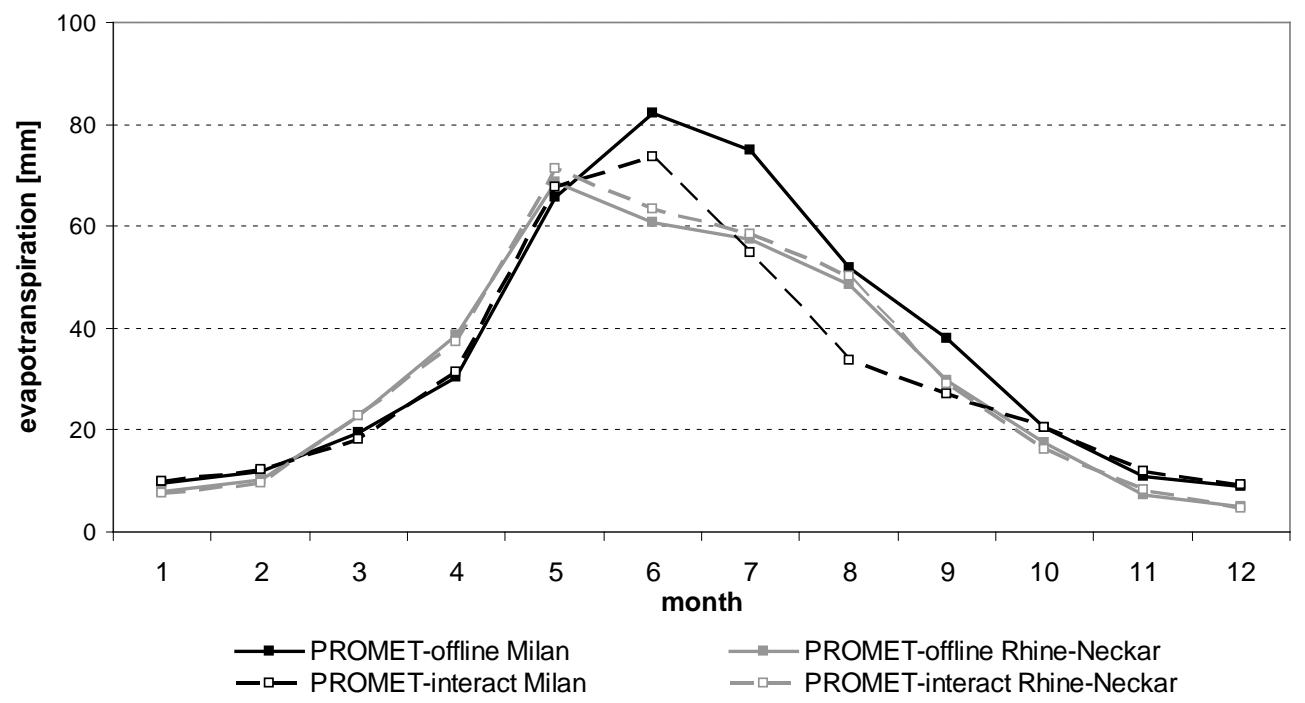

Fig. 14. Monthly evapotranspiration rates [mm] (1 January 1996-31 December 1999) of PROMET-offline simulation and PROMET-interact simulation exemplarily for the Milan and Rhine-Neckar pixels.

\subsubsection{Air temperature}

Figure 11 compares the annual mean near surface air temperature between the MM5 simulation either using the NOAHLSM or PROMET-interact. While the mean temperature over the coupling domain is $9.4^{\circ} \mathrm{C}$ in the MM5/PROMET-interact simulation, it is $8.5^{\circ} \mathrm{C}$ in the MM5/NOAH simulation. Despite the replacement of the NOAH-LSM, still a similar temperature can be reproduced within the MM5/PROMETinteract simulation with regional differences.

A higher net radiation in the MM5/PROMET-interact simulation than in the MM5/NOAH simulation as well as less evapotranspiration and, thus, less evaporative cooling result in mutually dependent higher near surface air temperature in the MM5/PROMET-interact simulation, except for mountainous regions. Here, snow cover plays a prominent role in the PROMET simulation, affecting sensible heat particularly in spring, when available energy is put into snow melt in the PROMET simulation, while energy is put into sensible heat resulting in increasing near surface air temperature in the NOAH simulation. Possible reasons for the different snow cover may be the use of different snow modules and scale issues due to different underlying DEMs.

The MM5 atmospheric model responses to the replacement of the NOAH-LSM with PROMET with higher temperatures by up to $2.4 \mathrm{~K}$ (in the Ruhr region) as shown in Fig. 11. While the annual mean near surface air temperature for the PROMET Milan pixels is $1.6 \mathrm{~K}$ warmer $\left(14.2^{\circ} \mathrm{C}\right)$ than the MM5/NOAH simulation $\left(12.6^{\circ} \mathrm{C}\right)$, maximum differences $(3.3 \mathrm{~K})$ appear in June, while in winter, when energy assumption at the land surface is low, temperature is hardly affected by feedbacks.

\subsubsection{Precipitation}

Besides temperature, precipitation is another parameter strongly interacting with the land surface and having large hydrological impacts on LSHMs. The changed lower boundary conditions in the PROMET-interact simulation result in less annual precipitation amounts, especially South of the Alps (Fig. 12). While the annual precipitation amount over the simulation area is $830 \mathrm{~mm}$ in the MM5/PROMETinteract simulation, it is $886 \mathrm{~mm}$ in the MM5/NOAH simulation. The spatial patterns of annual precipitation amounts between MM5/NOAH and MM5/PROMET-interact simulations are almost the same. However, total precipitation amounts decrease mostly North and South of the Alps and in the Po-Valley by up to $213 \mathrm{~mm}$ (Fig. 12).

Maximum differences compared to the MM5/NOAH simulation occur mainly in August, when almost $50 \mathrm{~mm}$ less precipitation is simulated for the Milan area by using the PROMET-interact land surface within MM5. Concerning the Milan pixels, the annual precipitation differs by $164 \mathrm{~mm}$ which is about $15 \%$. The decrease of total precipitation is difficult to diagnose. It is mainly based on a decrease of convective precipitation in summer. The different portioning of energy into sensible and latent heat overall results in an increase of sensible heat in the PROMET simulation, except for mountainous areas in winter and spring due to snow cover. With increasing sensible heat flux, the planetary boundary layer height is increasing which results in dryer air masses. As a result, cloud fraction and convection are inhibited and thus convective precipitation is decreasing especially in summer. 


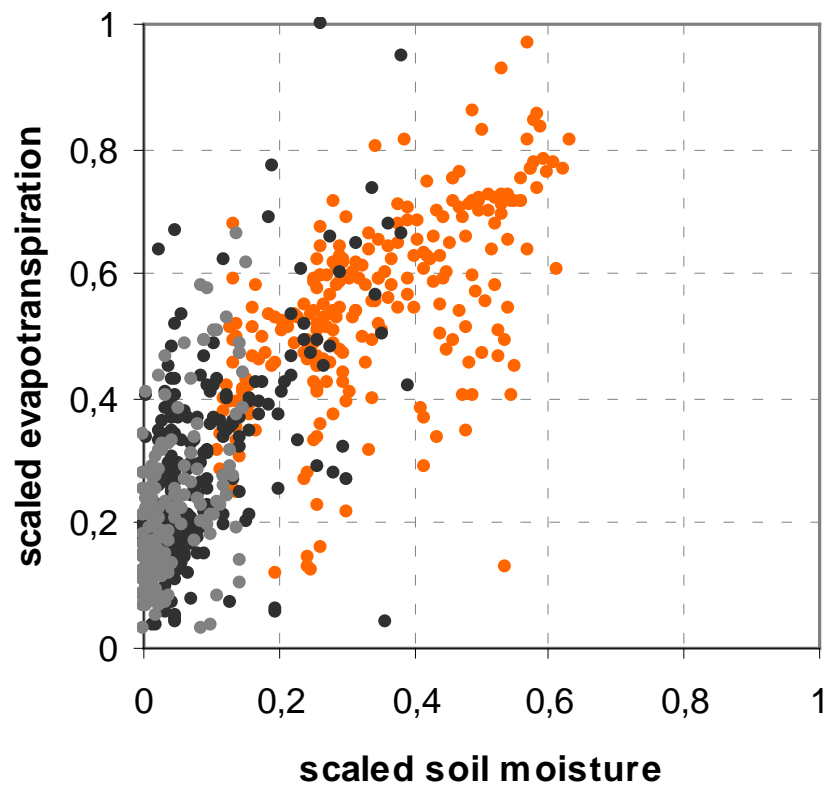

- NOAH • PROMET-offline - PROMET-interact

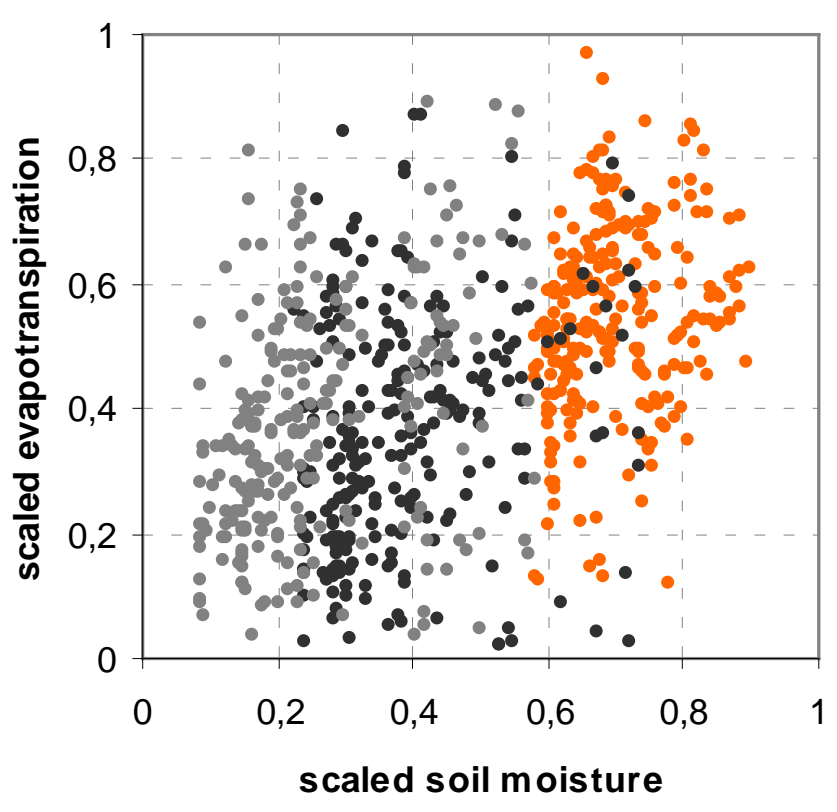

- NOAH • PROMET-offline - PROMET-interact

Fig. 15. Daily mean evapotranspiration (normalized by maximum) plotted against soil moisture of the third soil layer (scaled between wilting point and saturation) showing the PROMET-interact simulation in comparison to the PROMET-offline and NOAH results for the vegetated pixels of the Milan area (upper) and the Rhine-Neckar area (lower) for July and August (1996-1999).

\subsubsection{Evapotranspiration}

By allowing for feedbacks between the high resolution PROMET land surface and the MM5 atmosphere, the land surface in turn is affected by the changed atmospheric conditions. The impact of these feedback effects on evapotranspiration is shown in Fig. 13, thereby quantifying the inconsistencies between the offline and interactive coupling approach. Overall, the annual PROMET-interact evapotranspiration $(405 \mathrm{~mm})$ is a little higher than in the annual PROMET-offline simulation (397 mm).

However, a more detailed spatial analysis shows remarkably smaller annual evapotranspiration rates in the Mediterranean area South of the Alps while annual evapotranspiration rates slightly increased North of the Alps (Fig. 13). The highest impact of the feedbacks on evapotranspiration can be found in the Northern part of Italy, where evapotranspiration rates decreased by up to $150 \mathrm{~mm}$ due to dryer conditions.

For the Milan pixels, the annual distinction is approx. $55 \mathrm{~mm}$ which is $13 \%$ of the annual evapotranspiration. The inconsistencies of the offline coupling approach are most relevant in the summer months, when PROMETinteract shows decreased evapotranspiration rates, e.g., in July of up to $20 \mathrm{~mm}(27 \%)$, while in the winter months evapotranspiration is hardly affected by the feedback mechanisms (Fig. 14). When focusing on the Milan region, evapotranspiration decreased by $30 \%$ from July to September while at the same time temperature increased by $2.7 \mathrm{~K}$ and precipitation decreased by $37 \%$.

North of the Alps as exemplarily shown for the Rhine Neckar area, annual evapotranspiration slightly increased by $4 \mathrm{~mm} \mathrm{yr}^{-1}(1.9 \%)$. Thereby, the moderate increase mainly occurred from Mai to August and accounted for $3.2 \%$ (2 mm) (Fig. 14).

According to Fig. 10, Fig. 15 now shows the degree to which the soil moisture-evapotranspiration interaction is responsible for the sign of the feedback. For the Milan area PROMET-interact now operates in a yet drier regime. While plants' water suction already reached the wilting point in PROMET-offline simulations on several days (Fig. 10), feedback effects in the PROMET-interact simulations now result in an even drier soil where soil moisture is closer to the wilting point from July to August (Fig. 15). This results in a higher level of plants' water-stress, restricting transpiration more. North of the Alps, exemplarily shown for the RhineNeckar area, where precipitation is also reduced upon implementing PROMET into MM5, PROMET-interact also operates in a yet drier regime, however, far away from reaching the wilting point (Fig. 15). Thus, still enough soil water is available for plant transpiration and evaporation. Therefore, the feedbacks - especially the increased air temperature and radiation have predominantly positive effects on transpiration here. 


\section{Conclusions}

Offline driving a LSM with RCM output can lead to inconsistencies since feedbacks between the offline driven LSM and the RCM are not taken into account. The study has shown that considerable discrepancies occur between LSMs used within RCMs and downstream climate impact models. The different scales, parameterizations and formulations, however, describing identical land surface processes in the NOAH-LSM used within the RCM MM5 and the downstream hydrological model PROMET contribute to the inconsistencies. Consequently, net radiation was higher in the PROMET-offline simulation due to different albedo and emissivity settings. The different redistribution of this net radiation into sensible and latent heat resulted in an overall higher Bowen ratio due to e.g., more impermeable areas (such as urban areas) in the PROMET land use while the NOAH-LSM assumes the land surface to rather homogeneously consist of arable land for the coupling domain. Finally, different soil hydraulics due to different soil/plant parameterizations and different physical formulations lead to considerable hydrological differences which resulted in lower soil moisture and lower evapotranspiration.

By coupling PROMET interactively with the RCM MM5, thereby substituting the NOAH-LSM, PROMET provides the lower boundary conditions to the atmospheric part of MM5. Subsequently, the scaling interface SCALMET closes the scale gap between the models and ensures mass- and energy conservation within the down- and the upscaling of linear and nonlinear energy fluxes. Consequently, the atmosphere responded to the replacement of the LSM with increased annual air temperatures by up to $2 \mathrm{~K}$ and decreased annual precipitation by up to $213 \mathrm{~mm}$ mainly due to less convection in summer.

Finally, by comparing the offline driven and the interactive simulation, we were able to quantify the inconsistencies that occur when neglecting the feedbacks. The study has shown that the inconsistencies that arise when using PROMET offline instead of interactively coupled with MM5 are strong (up to $150 \mathrm{~mm} \mathrm{yr}^{-1}$ ) and, therefore, may not be neglected. Further, we demonstrated that these inconsistencies can affect evapotranspiration positively as well as negatively, depending on the prevailing hydrological conditions. The temperature increase and precipitation decrease led to drier conditions in the interactively coupled simulation. As a result, evapotranspiration decreased in regions mainly South of the Alps with already dry conditions in summer, where soil moisture was close to the wilting point. Thereby, evapotranspiration decreased by $30 \%$ from June to September, e.g., for the Milan area. North of the Alps, however, the level of soil moisture was far away from reaching the wilting point due to more humid conditions than in the Mediterranean area. The feedbacks affected evapotranspiration positively here, due to increased temperature and more radiation. Although precipitation decreased, still enough soil water was available for plant transpiration and evaporation. The impact of the feedbacks on evapotranspiration was almost negligible in winter, but considerably high in the summer months, when energy conversion at the land surface is high, finally resulting in greater feedbacks.

Further studies will compare the offline and interactive coupling approach with observation data for annual, monthly, and diurnal time series.

Acknowledgements. The research described in this paper was carried out at the Department of Geography of the LudwigMaximilians-Universität in Munich, Germany as part of the GLOWA-Danube project, which was funded by BMBF (Federal Ministry of Education and Research) from 2000 to 2010. The support is gratefully acknowledged. The authors want to thank the Editor Bart van den Hurk and the anonymous reviewers for their valuable remarks which considerably improved the paper.

Edited by: B. van den Hurk

\section{References}

Bach, H. and Verhoef, W.: Sensitivity studies on the effect of surface soil moisture on canopy reflectance using the radiative transfer model GeoSAIL, Igarss 2003, IEEE Int. Geosci. Remote Se., 1-4, 1679-1681, 2003.

Baldocchi, D. D., Hicks, B. B., and Camara, P.: A canopy stomatal resistance model for gaseous deposition to vegetated surfaces, Atmos. Environ., 21, 91-101, doi:10.1016/00046981(87)90274-5, 1987.

Campbell, G. S. and Norman, J. M.: An Introduction To Environmental Biophysics, Second Edition, Springer, New York, 2000.

Chen, F. and Dudhia, J.: Coupling an Advanced Land SurfaceHydrology Model with the Penn State-NCAR MM5 Modeling System. Part I: Model Implementation and Sensitivity, Mon. Weather Rev., 129, 569-585, 2001a.

Chen, F. and Dudhia, J.: Coupling an Advanced Land SurfaceHydrology Model with the Penn State-NCAR MM5 Modeling System. Part II: Preliminary Model Validation, Mon. Weather Rev., 129, 587-604, 2001b.

Chen, F., Mitchell, K., Schaake, J., Xue, Y., Pan, H.-L., Koren, V., Duan, Q. Y., Ek, M., and Betts, A.: Modeling of land surface evaporation by four schemes and comparison with FIFE observations, J. Geophys. Res., 101, 7251-7268, doi:10.1029/95JD02165, 1996.

Daly, C., Gibson, W. P., Taylor, G. H., Johnson, G. L., and Pasteris, P.: A knowledge-based approach to the statistical mapping of climate, Clim. Res., 22, 99-113, 2002.

Dickinson, R. E., Henderson-Sellers, A., Rosenzweig, C., and Sellers, P. J.: Evapotranspiration models with canopy resistance for use in climate models, a review, Agr. Forest Meteorol., 54, 373 388, doi:10.1016/0168-1923(91)90014-h, 1991.

Essery, R. L. H., Best, M. J., Betts, R. A., and Cox, P. M.: Explicit Representation of Subgrid Heterogeneity in a GCM Land Surface Scheme, J. Hydrometeorol., 4, 530-543, 2003.

Fischer, E. M., Seneviratne, S. I., Vidale, P. L., Lüthi, D., and Schär, C.: Soil Moisture-Atmosphere Interactions during the $2003 \mathrm{Eu}-$ ropean Summer Heat Wave, J. Climate, 20, 5081-5099, 2007. 
Ge, J., Qi, J., Lofgren, B. M., Moore, N., Torbick, N., and Olson, J. M.: Impacts of land use/cover classification accuracy on regional climate simulations, J. Geophys. Res., 112, 12, doi:10.1029/2006JD007404, 2007.

Gutman, G. and Ignatov, A.: Satellite-derived green vegetation fraction for the use in numerical weather prediction models, Adv. Space Res., 19, 477-480, doi:10.1016/s0273-1177(97)00058-6, 1997.

Hagemann, S., Botzet, M., and Machenhauer, B.: The summer drying problem over south-eastern europe: sensitivity of the limited area model HIRHAM4 to improvements in physical parameterization and resolution, Phys. Chem. Earth, PT B, 26, 391-396, doi:10.1016/s1464-1909(01)00024-7, 2001.

Henderson-Sellers, A., Dickinson, R. E., and Pitman, A. J.: Atmosphere-landsurface modelling, Math. Comput. Model., 21, 5-10, doi:10.1016/0895-7177(95)00045-4, 1995.

Henderson-Sellers, A., Irannejad, P., and McGuffie, K.: Future desertification and climate change: The need for land-surface system evaluation improvement, Global Planet. Change, 64, 129138, doi:10.1016/j.gloplacha.2008.06.007, 2008.

IPCC: Climate Change 2007: Impacts, Adaptation and Vulnerability. Contribution of Working Group II to the Fourth Assessment Report of the Intergovernmental Panel on Climate Change, Cambridge University Press, Cambridge, United Kingdom and New York, NY, USA., 976 pp., 2007.

Jarvis, P. G.: The Interpretation of the Variations in Leaf Water Potential and Stomatal Conductance Found in Canopies in the Field, Philos. T. Roy. Soc. B, 273, 593-610, 1976.

Koster, R. D. and Suarez, M. J.: The components of a 'SVAT' scheme and their effects on a GCM's hydrological cycle, Adv. Water Resou., 17, 61-78, doi:10.1016/0309-1708(94)90024-8, 1994.

Koster, R. D., Dirmeyer, P. A., Guo, Z. C., Bonan, G., Chan, E., Cox, P., Gordon, C. T., Kanae, S., Kowalczyk, E., Lawrence, D., Liu, P., Lu, C. H., Malyshev, S., McAvaney, B., Mitchell, K., Mocko, D., Oki, T., Oleson, K., Pitman, A., Sud, Y. C., Taylor, C. M., Verseghy, D., Vasic, R., Xue, Y. K., Yamada, T., and Team, G.: Regions of strong coupling between soil moisture and precipitation, Science, 305, 1138-1140, 2004.

Kotlarski, S., Block, A., Böhm, U., Jacob, D., Keuler, K., Knoche, R., Rechid, D., and Walter, A.: Regional climate model simulations as input for hydrological applications: Evaluation of uncertainties., Adv. Geosci., 5, 119-125, 2005, http://www.adv-geosci.net/5/119/2005/.

Liston, G. E. and Elder, K.: A Meteorological Distribution System for High-Resolution Terrestrial Modeling (MicroMet), J. Hydrometeorol., 7, 217-234, 2006.

Marke, T.: Development and Application of a Model Interface To couple Land Surface Models with Regional Climate Models For Climate Change Risk Assessment In the Upper Danube Watershed, Fakultät für Geowissenschaften, Ludwig-MaximiliansUniversität, München, 2008.

Marke, T., Mauser, W., Pfeiffer, A., and Zängl, G.: A pragmatic approach for the downscaling and bias correction of regional climate simulations: evaluation in hydrological modeling, Geosci. Model Dev., 4, 759-770, doi:10.5194/gmd-4-759-2011, 2011.

Martin, P. H.: Land-surface characterization in climate models: biome-based parameter inference is not equivalent to local direct estimation, J. Hydrol., 212-213, 287-303, doi:10.1016/s0022-
1694(98)00212-1, 1998.

Mauser, W. and Bach, H.: PROMET - Large scale distributed hydrological modelling to study the impact of climate change on the water flows of mountain watersheds, J. Hydrol., 376, 362-377, doi:10.1016/j.jhydrol.2009.07.046, 2009.

Mitchell, K.: The Community Noah Land-Surface Model (LSM), 2005.

Molod, A. and Salmun, H.: A global assessment of the mosaic approach to modeling land surface heterogeneity, J. Geophys. Res., 107, 4217, doi:10.1029/2001jd000588, 2002.

Orlowsky, B. and Seneviratne, S. I.: Statistical Analyses of LandAtmosphere Feedbacks and Their Possible Pitfalls, J. Climate, 23, 3918-3932, 2010.

Pfeiffer, A. and Zängl, G.: Validation of climate-mode MM5simulations for the European Alpine Region, Theoretical Applied Climatology, 101, 93-108, doi:10.1007/s00704-009-01995, 2009.

Pitman, A. J.: The evolution of, and revolution in, land surface schemes designed for climate models, Int. J. Climatol., 23, 479510, doi:10.1002/joc.893, 2003.

Richter, K. and Timmermans, W. J.: Physically based retrieval of crop characteristics for improved water use estimates, Hydrol. Earth Syst. Sci., 13, 663-674, doi:10.5194/hess-13-663-2009, 2009.

Schär, C., Vidale, P. L., Lüthi, D., Frei, C., Häberli, C., Liniger, M. A., and Appenzeller, C.: The role of increasing temperature variability in European summer heatwaves, Nature, 427, 332336, 2004.

Seth, A., Giorgi, F., and Dickinson, R. E.: Simulating fluxes from heterogeneous land surfaces - explicit subgrid method employing the biosphere-atmosphere transfer scheme (BATS), J. Geophys. Res.-Atmos., 99, 18651-18667, 1994.

Teuling, A. J., Stöckli, R., and Seneviratne, S. I.: Bivariate colour maps for visualizing climate data, Int. J. Climatol., 31, 14081412, doi:10.1002/joc.2153, 2011.

Uppala, S. M., Kallberg, P. W., Simmons, A. J., Andrae, U., Bechtold, V. D. C., Fiorino, M., Gibson, J. K., Haseler, J., Hernandez, A., Kelly, G. A., Li, X., Onogi, K., Saarinen, S., Sokka, N., Allan, R. P., Andersson, E., Arpe, K., Balmaseda, M. A., Beljaars, A. C. M., Berg, L. V. D., Bidlot, J., Bormann, N., Caires, S., Chevallier, F., Dethof, A., Dragosavac, M., Fisher, M., Fuentes, M., Hagemann, S., Hólm, E., Hoskins, B. J., Isaksen, L., Janssen, P. A. E. M., Jenne, R., McNally, A. P., Mahfouf, J.-F., Morcrette, J.-J., Rayner, N. A., Saunders, R. W., Simon, P., Sterl, A., Trenberth, K. E., Untch, A., Vasiljevic, D., Viterbo, P., and Woollen, J.: The ERA-40 Re-analysis., Q. J. Roy. Meteorol. Soc., 131, 2961-3012, doi:10.1256/qj.04.176, 2005.

Yang, Z.-L., Dickinson, R. E., Shuttleworth, W. J., and Shaikh, M.: Treatment of soil, vegetation and snow in land surface models: a test of the Biosphere-Atmosphere Transfer Scheme with the HAPEX-MOBILHY, ABRACOS and Russian data, J. Hydrol., 212-213, 109-127, doi:10.1016/s0022-1694(98)00205-4, 1998.

$\mathrm{Yu}, \mathrm{Z}$.: Assessing the response of subgrid hydrologic processes to atmospheric forcing with a hydrologic model system, Global Planet. Change, 25, 1-17, doi:10.1016/s0921-8181(00)00018-7, 2000.

Zabel, F., Hank, T. B., and Mauser, W.: Improving arable land heterogeneity information in available land cover products for land surface modelling using MERIS NDVI data, Hydrol. Earth Syst. 
Sci., 14, 2073-2084, doi:10.5194/hess-14-2073-2010, 2010.

Zängl, G.: An improved method for computing horizontal diffusion in a sigma-coordinate model and its application to simulations over mountainous topography., Mon. Weather Rev., 130, 14231432, 2002.
Zeng, X. M., Zhao, M., Su, B. K., Tang, J. P., Zheng, Y. Q., Zhang, Y. J., and Chen, J.: Effects of the land-surface heterogeneities in temperature and moisture from the "combined approach" on regional climate: a sensitivity study, Global Planet. Change, 37, 247-263, doi:10.1016/s0921-8181(02)00209-6, 2003. 